\title{
New species of Ehrlichia isolated from Rhipicephalus (Boophilus) microplus shows an ortholog of the $E$. canis major immunogenic glycoprotein gp36 with a new sequence of tandem repeats
}

Alejandro Cabezas Cruz ${ }^{1}$, Erich Zweygarth², Mucio Flavio Barbosa Ribeiro ${ }^{3}$, Julia Angelica Gonçalves da Silveira ${ }^{3}$, Jose de la Fuente ${ }^{4,5}$, Libor Grubhoffer ${ }^{1}$, James J Valdés ${ }^{1}$ and Lygia Maria Friche Passos ${ }^{2,6^{*}}$

\begin{abstract}
Background: Ehrlichia species are the etiological agents of emerging and life-threatening tick-borne human zoonoses that inflict serious and fatal infections in companion animals and livestock. The aim of this paper was to phylogeneticaly characterise a new species of Ehrlichia isolated from Rhipicephalus (Boophilus) microplus from Minas Gerais, Brazil.

Methods: The agent was isolated from the hemolymph of Rhipicephalus (B.) microplus engorged females that had been collected from naturally infested cattle in a farm in the state of Minas Gerais, Brazil. This agent was then established and cultured in IDE8 tick cells. The molecular and phylogenetic analysis was based on 165 rRNA, groEL, $d s b, g l t A$ and gp36 genes. We used the maximum likelihood method to construct the phylogenetic trees.

Results: The phylogenetic trees based on 165 rRNA, groEL, dsb and gltA showed that the Ehrlichia spp isolated in this study falls in a clade separated from any previously reported Ehrlichia spp. The molecular analysis of the ortholog of gp36, the major immunoreactive glycoproteins in E. canis and ortholog of the E. chaffeensis gp47, showed a unique tandem repeat of 9 amino acids (VPAASGDAQ) when compared with those reported for $E$. canis, E. chaffeensis and the related mucin-like protein in E. ruminantium.
\end{abstract}

Conclusions: Based on the molecular and phylogenetic analysis of the $16 \mathrm{~S} r R N A$, groEL, dsb and gltA genes we concluded that this tick-derived microorganism isolated in Brazil is a new species, named E. mineirensis (UFMG-EV), with predicted novel antigenic properties in the gp36 ortholog glycoprotein. Further studies on this new Ehrlichia spp should address questions about its transmissibility by ticks and its pathogenicity for mammalian hosts.

Keywords: Ehrlichia spp, Rhipicephalus (Boophilus) microplus, Phylogenetic analysis, Gp36 major immunogenic protein

\footnotetext{
* Correspondence: Lygia.Passos@lmu.de

${ }^{2}$ Comparative Tropical Medicine and Parasitology,

Ludwig-Maximilians-Universität München, Munich, Germany

${ }^{6}$ Departamento de Medicina Veterinaria Preventiva, INCT-Pecuária, Escola de

Veterinária-UFMG, Belo Horizonte, Minas Gerais, Brazil

Full list of author information is available at the end of the article
} 


\section{Background}

The emergence of multiple Ehrlichia species as etiological agents of newly discovered human zoonoses and the previous recognition of these agents as causing serious disease in companion animals and livestock have intensified the interest in these pathogens. Ehrlichiae are tick-transmitted obligate intracellular gram-negative bacteria that are maintained in nature by persistent infection of mammalian hosts [1]. They are microorganisms residing within the cytoplasmic vacuoles of monocytes, granulocytes, or platelets of humans and animals. Ehrlichia species elicit illnesses with fever, headache, leukopenia, and thrombocytopenia [2].

The obligately intracellular alpha-proteobacterial genus Ehrlichia (Rickettsiales: Anaplasmataceae) is spread all over the world and are comprised of five recognized species that are tick-transmitted, with three of the five causing human ehrlichiosis (E. canis, E. chaffeensis, and E. ewingii) [3]. The agent that causes the veterinary disease heartwater (E. ruminantium) can potentially infect humans [2,4] and Ehrlichia muris has not been associated with human infection. In addition, numerous candidate entities have been reported ("E. walkerii", "E. shimanensis", "Ixodes ovatus ehrlichia", "Panola Mountain ehrlichia", etc.), all isolated from hard ticks and mainly characterized by PCR sequencing [3]. To date, only three species of the genus Ehrlichia have been reported in Brazil: E. canis, E. ewingii and E. chaffeensis [5].

Different hard ticks species have been associated with transmitting members of the genus Ehrlichia: Rhipicephalus sanguineus and Dermacentor variabilis (E. canis), Amblyomma americanum [6] and Dermacentor variabilis [5] (E. chaffeensis and E. ewingii), Haemaphysalis spp and Ixodes spp (E. muris) and Amblyomma spp (E. ruminantium) [6].

Polyphasic taxonomy has been advocated to ensure well-balanced determination of taxonomic relationships [7]. Different genes have been proposed to classify ehrlichial agents. The most widely used are $16 \mathrm{~S}$ rRNA [8,9], groESL operon [10], groEL gene [11], gltA [7], $d s b$ [12], gp36 and gp19 [13]. The gp36 belong to the group of major immunogenic antigen in $E$. canis (gp36) and E. chaffeensis (gp47) and both are orthologs to the mucin-like protein in E. ruminantium. These glycoproteins have tandem repeats that contain major B-cell epitopes with carbohydrate determinants, which contribute substantially to the immunoreactivity of these proteins. Only five types of tandem repeats have been characterized [14]. Of these glycoproteins, gp36 is the most divergent gene among E. canis isolates [15]. Nevertheless, the tandem repeat is highly conserved among different isolates, changing only in the number of repeats [13] and in few amino acids among E. canis isolates [15].
Recently, we have isolated an organism from hemolymph of $R$. (B.) microplus engorged females which had been collected from naturally infested cattle in Brazil (unpublished data). This organism has been propagated continuously in vitro, both in a tick cell line (IDE8) and in a monocyte-macrophage cell line from a dog (DH82), and has been initially characterised as a new genotype of Ehrlichia spp (UFMG-EV strain) [16]. In the present study we report further molecular and phylogenetic analyses focusing on five genes (16S rRNA, groESL, gltA, $d s b$ and gp36) of this new organism, from now on referred as Ehrlichia mineirensis (UFMG-EV).

\section{Methods}

\section{Organism isolation and in vitro cultivation}

Eleven $R$. (B.) microplus engorged females, larger than $4.5 \mathrm{~mm}$ in length, were collected from naturally infested calves (4 to 6 months old) from a farm in Minas Gerais, Brazil. The ticks were washed, blotted dry, and disinfected with Germekil (Johnson, Brazil.), for 30 minutes at room temperature. After several washes in sterile distilled water, the ticks were individually placed into polystyrene plates and were incubated at $27^{\circ} \mathrm{C}$ and relative humidity over $83 \%$. After a 10 -day incubation period hemolymph were collected to provide material for infecting IDE8 cells [17]. Each tick was held with sterile forceps, the cuticula was again sterilized, as previously described, and the leg cut with a sterile scalpel blade. The hemolymph was collected using a capillary tube to gather the draining fluid. Hemolymph from three ticks were pooled in a tube containing $200 \mu \mathrm{l}$ of culture medium, which constitute the inoculum to infect one culture flask containing an on growing IDE8 cell monolayer.

After infection, the culture flask was monitored daily by examination of cytocentrifuge smears made from $50 \mu \mathrm{l}$ aliquots taken from the culture suspension. Smears were fixed twice with methanol (for $10 \mathrm{~min}$ ), stained with an $8 \%$ Giemsa solution for $30 \mathrm{~min}$ and examined under oil immersion at 1,000x magnification. The first infected cells were detected 28 days after culture initiation.

Maintenance of cultures was carried out with medium changes weekly. Briefly, IDE8 cells were maintained at $32^{\circ} \mathrm{C}$ in L-15B medium [18], supplemented with $5 \%$ heat-inactivated foetal bovine serum, $10 \%$ tryptose phosphate broth, $0.1 \%$ bovine lipoprotein concentrate (MP Biomedicals, Santa Ana, CA, USA), $100 \mathrm{IU} / \mathrm{ml}$ penicillin and $100 \mu \mathrm{g} / \mathrm{ml}$ streptomycin. Infected IDE8 cultures were propagated in a modified L-15B medium as outlined above, further supplemented with $0.1 \% \mathrm{NaHCO}_{3}$ and $10 \mathrm{mM}$ HEPES. The $\mathrm{pH}$ of the medium was adjusted to 7.5 with $1 \mathrm{~N} \mathrm{NaOH}$. Infected cultures were propagated at $34^{\circ} \mathrm{C}$ in $25 \mathrm{~cm}^{2}$ plastic culture flasks in 
$5 \mathrm{ml}$ of the medium under normal atmospheric conditions.

\section{Genomic DNA isolation}

The DNeasy Blood \& Tissue Kit (Qiagen Inc. Valencia, Calif.) was used for extraction of DNA from infected IDE8 cells. DNA extraction was performed according to the manufacturer's instructions. The extracted material was eluted from the columns in $100 \mu \mathrm{l}$ of sterile double distilled $\mathrm{H}_{2} \mathrm{O}$ (ddH2O), and the DNA concentration and purity were determined by measuring the optical density at both 260 and $280 \mathrm{~nm}$ with a DNA-RNA calculator (NanoDrop ${ }^{\circledR}$ ND-1000, Peqlab, Erlangen, Germany). Ten-fold dilutions were done with the genomic DNA and separated in aliquot of $10 \mu \mathrm{l}$ each and kept frozen until their use in a PCR reaction.

\section{PCR}

The primers used in this study are shown in (Table 1). The oligonucleotide primers used for the amplification of $d s b$ gene and gltA gene were designed for this study using primer design software (PrimerSelect; DNAStar, USA) and information from the E. canis genome [GenBank: CP000107] [19]. Two independent PCR reactions were performed for each gene. For each PCR amplification, $2 \mu \mathrm{L}$ of extracted DNA was used as the template in a $25 \mu \mathrm{L}$ reaction mixture containing $20 \mathrm{pmol}$ of each primer and 2X PCR Master Mix (Promega, USA). The reactions were conducted in an Eppendorf thermocycler (Eppendorf Mastercycler personal AG, 22331 Hamburg, Germany) according to the parameters: $2 \mathrm{~min}$ at $94^{\circ} \mathrm{C}$ followed by 40 cycles of $30 \mathrm{sec}$ at $94^{\circ} \mathrm{C}, 1 \mathrm{~min}$ at $45^{\circ} \mathrm{C}$, and $1.5 \mathrm{~min}$ at $72^{\circ} \mathrm{C}$ with a final extension step of $5 \mathrm{~min}$. The PCR products were stained using an Ethidium bromide free system, 6X Orange DNA Loading Dye (Thermo Scientific, Germany) and visualized in $0.8 \%$ agarose minigels.

\section{Cloning and sequencing}

The resulting PCR products were electrophoresed on a $0.8 \%$ agarose gel. The size of the amplified fragments was checked by comparison to a DNA molecular weight marker (100-bp DNA Ladder; Promega, USA). In each case, the single amplified product of the expected size was column purified using the QIAquick PCR Purification Kit (Qiagen, USA) and then ligated into the TOPO TA Cloning Kit (Invitrogen, USA) for subsequent transformation in Escherichia coli TOP 10 Chemically Competent cells. For each gene, five individuals clones containing the cloned fragment in the TOPO vector were purified using the QIAprep Spin Miniprep Kit (Qiagen, USA) and prepared for sequencing using an ABI 3130 sequencer (Applied Biosystems, USA) and the Big Dye Terminator v3.1 Cycle Sequencing Kit (Applied Biosystems, USA) with the M13F and M13R vector primer. Both the sense and antisense strands of each PCRamplified product were sequenced, and the sequences were then manually edited to resolve any ambiguities. A consensus sequence was obtained for each amplified PCR product by comparing both the sense and antisense sequences from the five clones.

\section{DNA sequence analysis}

To find the homology of our sequences we used the database Nucleotide collection (nr/nt) using Megablast (optimize for highly similar sequences) from the BLAST server [20]. Nucleotide sequences were aligned using BLAST [20] and protein sequences were aligned using the multiple-alignment program CLUSTALW [21]. The homology between sequences was analyzed using MegAlign, DNAStar, USA. Nucleotide sequences were translated to amino acid (aa) sequence by the ExPASy translation tool of the Swiss Institute of Bioinformatics [22].

The phylogenetic analysis was performed as follows: sequences were aligned with MUSCLE (v3.7) configured

Table 1 Primers used in this study for the amplification of the $16 S$ rRNA, groESL, gltA, dsb and gp36 genes from E. mineirensis (UFMG-EV) genomic DNA

\begin{tabular}{|c|c|c|c|}
\hline Target & Primers* & Sequence & Expected size $(\mathrm{Kb})$ \\
\hline \multirow[t]{2}{*}{$16 S r R N A$} & $8 \mathrm{~F}^{9}$ & $5^{\prime}$ - AGTTTGATCATGGCTCAG - $3^{\prime}$ & 1.4 \\
\hline & $1448 R$ & $5^{\prime}$ - CCATGGCGTGACGGGCAGTGTG - 3' & \\
\hline \multirow[t]{2}{*}{ groEL } & $\mathrm{HS} 1^{10}$ & $5^{\prime}-\mathrm{TGGGCTGGTA(A/C)TGAAAT}-3^{\prime}$ & 1.4 \\
\hline & $\overline{H S 6}$ & 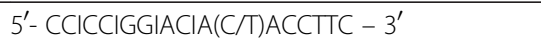 & \\
\hline \multirow[t]{2}{*}{ gltA } & gltAF1 & 5'- CTTCTGATAAGATTTGAAGTGTTTG - 3' & 1.5 \\
\hline & gltAR1 & $5^{\prime}$ - CTTTACAGTACCTATGCATATCAATCC - $3^{\prime}$ & \\
\hline \multirow[t]{2}{*}{$\overline{d s b}$} & $\mathrm{dsbF2}$ & $5^{\prime}$ - CTTAGTAATACTAGTGGCAAGTTTCCAC - $3^{\prime}$ & 0.683 \\
\hline & $\mathrm{dsbR2}$ & 5'- GTTGATATATCAGCTGCACCACCG - 3' & \\
\hline \multirow[t]{2}{*}{ gp36 } & EC36-F1 $1^{13}$ & 5'- GTATGTTTCTITTATATCATGGC - 3' & 1.0 \\
\hline & $\overline{E C 36-R 1}$ & 5'- GGTTATATTTCAGTTATCAGAAG - 3' & \\
\hline
\end{tabular}


for highest accuracy [23]. After alignment, ambiguous regions (i.e., containing gaps and/or poorly aligned) were removed with Gblocks (v0.91b) [24]. The phylogenetic tree was reconstructed using the maximum likelihood method implemented in the PhyML program (v3.0 aLRT) [25,26]. Reliability for internal branch was assessed using the bootstrapping method (100 bootstrap replicates). Graphical representation and edition of the phylogenetic tree were performed with TreeDyn (v198.3) [27]. The nomenclature used in the trees is according to Dumler et al., [19]. The same analysis of similarity and phylogenetic relationships was performed for the genes $16 S$ rRNA, groEL, gltA and $d s b$ with the exception that the $d s b$ tree is unrooted and the rest are rooted.

\section{Analysis of the glycoprotein gp36 gene and putative aa sequence}

The gp36 ortholog was tested for the presence of signal peptide sequences with the computational algorithm SignalP trained on gram-negative bacteria [28]. The gp36 protein sequence was evaluated for potential mucin-type O-linked glycosylation on serines and threonines with the computational algorithm NetOGlyc v3.1 [29] and for N-linked glycosylation was used the NetNGlyc 1.0 Server [30]. The Tandem Repeats Finder database [31] was used to analyze the tandem repeats. The prediction of continuous B cell epitopes was done using the B cells Epitopes Prediction Tool [32] and the 3D structure of the glycoprotein and the predicted epitopes was obtained using the algorithm contained in the ElliPro epitope modeling tool and sequences available in the ElliPro server [33]. As previously reported [14], for the convenience of sequence comparison the gp36 gene orthologs were divided into three regions: $5^{\prime}$ end prerepeat region, a tandem repeat region, and 3 ' end postrepeat region.

\section{Sequences used in this study}

The sequences obtained from Ehrlichia mineirensis (UFMG-EV) have been deposited in GeneBank, and their accession numbers are: 16S rRNA [GenBank: JX629805], groESL [GenBank: JX629806], $d s b$ [GenBank: JX629808], gltA [GenBank: JX629807] and gp36 [GenBank: JX629809]. The $16 S$ rRNA, groEL, gltA, $d s b$ and gp36 sequences used for the phylogenetic tree or molecular analysis in general were obtained from GenBank and their accession numbers are show in the Tables and Figures where they have been mentioned.

\section{Results}

Sequence analysis of $16 \mathrm{~S}$ rRNA

In order to obtain relevant information from $16 S$ rRNA at the species level, the primers $8 \mathrm{~F}$ and $1448 \mathrm{R}$ were used to isolate a fragment of $\sim 1.4 \mathrm{~Kb}$. Approximately a $1.4 \mathrm{~Kb}$ amplicon corresponding to the expected size of targeted 16S rRNA gene fragment was obtained (data not shown). A consensus sequence of $1.384 \mathrm{~Kb}$ was obtained from 2 independent PCRs and five clones were sequenced. In total, our sequence had 10 changes of nucleotides when compared with E. canis [GenBank: GU810149] with two insertions and three deletions (data not shown). The percent of identities with all the members of the Ehrlichia genus are shown in the Table 2 upper triangle. Figure 1A shows the tree build using the maximum likelihood method; it shows that E. mineirensis (UFMG-EV) falls in a clade separated from all the previous reported sequences. The tree build with the neighbour joining method using the Kimura 2 parameters substitution model show identical results (data not shown).

The gene $16 S$ rRNA has a highly variable region located at the 5 ' end of the gene [8]. This fragment is useful in identifying Ehrlichia spp [9]. Figure 2 shows three changes in nucleotides in E. mineirensis (UFMG$\mathrm{EV}$ ) in comparison with $E$. canis and seven changes in nucleotides when compare with Ehrlichia. sp. Tibet which was isolated from $R$. microplus [8].

\section{Sequence analysis of $d s b$}

The amplicon obtained from the PCR set up with the primers dsbF2 and dsbR2 gave a band with the expected size of $0.7 \mathrm{~Kb}$. A fragment of $0.683 \mathrm{~Kb}$ of the gene $d s b$ was obtained and sequenced. Dsb gene sequences for available Ehrlichia spp. were aligned using clustalW. The alignment shows that $d s b$ gene is conserved $(76.4 \%$ 94.7\%) within the genus (Table 2 lower triangle). The aa sequence shows homology from $72.0 \%$ to $95.0 \%$ with $E$. ruminantium [GenBank: AF308669, clon 18hw] and $E$. canis [GenBank: AF403710], respectively. When compared with the complete dsb from E. canis [AF403710] 10 aa changes are observed (data not shown). The changes are concentrated at the carboxyl-terminus of the protein. Different dsb isolates of $E$. canis share $100 \%$ of identity among them (Table 3 ) The phylogenetic tree shows that E. mineirensis (UFMG-EV) $d s b$ is separated from its homologs in other species of the Ehrlichia genus (Figure 3).

\section{Sequence analysis of groESL operon}

The amplification with primers HS1-HS6 produced a PCR product in the expected size $1.4 \mathrm{~Kb}$. The nucleotide sequences of the PCR products amplified from E. mineirensis (UFMG-EV) contained a reading frame corresponding to the 26 aa carboxyl-terminus of groES, 416 aa of the amino-terminal end of groEL, and the spacer between them. The length of the nucleotide sequence of the spacer region in the sequence reported here were 95 
Table 2 Identities comparison of $16 S$ rRNA and dsb genes between $E$. mineirensis (UFMG-EV) and other members of the genus Ehrlichia

\begin{tabular}{|c|c|c|c|c|c|c|}
\hline \multicolumn{7}{|c|}{ Percent of nucleotide similarity of $16 \mathrm{~S} r R N A^{*}$} \\
\hline & $\begin{array}{l}\text { Ehrlichia mineirensis } \\
\text { (UFMG-EV) }\end{array}$ & $\begin{array}{c}\text { E. canis } \\
\text { [GU810149] }\end{array}$ & $\begin{array}{l}\text { E. chaffeensis } \\
\text { [AF147752] }\end{array}$ & $\begin{array}{l}\text { E. ewingii } \\
\text { [U96436] }\end{array}$ & $\begin{array}{c}\text { E. muris } \\
\text { [AB013008] }\end{array}$ & $\begin{array}{l}\text { E. ruminantium } \\
\text { [AF069758] }\end{array}$ \\
\hline $\begin{array}{l}\text { Ehrlichia mineirensis } \\
\text { (UFMG-EV) }\end{array}$ & $* * *$ & 98.3 (16SrRNA) & 96.9 (16SrRNA) & 96.4 (16SrRNA) & 94.5 (16SrRNA) & 95.0 (16SrRNA) \\
\hline $\begin{array}{l}\text { Ehrlichia canis } \\
\text { [AF403710] }\end{array}$ & $94.7(d s b)$ & $* * *$ & 98.4 (16SrRNA) & 97.9 (16SrRNA) & 97.1 (16SrRNA) & $97.2(16 S r R N A)$ \\
\hline $\begin{array}{l}\text { Ehrlichia chaffeensis } \\
\text { [AF403711] }\end{array}$ & $82.3(d s b)$ & $83.5(d s b)$ & *** & 98.1 (16SrRNA) & 97.6 (16SrRNA) & 96.9 (16SrRNA) \\
\hline $\begin{array}{l}\text { Ehrlichia ewingii } \\
\text { [AY428950] }\end{array}$ & $78.6(d s b)$ & $76.9(d s b)$ & $78.0(d s b)$ & $* * *$ & $97.2(16 S r R N A)$ & 97.1 (16SrRNA) \\
\hline $\begin{array}{l}\text { Ehrlichia muris } \\
\text { [AY236484] }\end{array}$ & $81.1(d s b)$ & $81.1(d s b)$ & $84.5(d s b)$ & $77.2(d s b)$ & $* * *$ & 96.4 (16SrRNA) \\
\hline $\begin{array}{l}\text { Ehrlichia ruminantium } \\
\text { [AF308669] }\end{array}$ & $76.9(d s b)$ & $74.6(d s b)$ & $77.1(d s b)$ & $76.6(d s b)$ & $76.4(d s b)$ & $* * *$ \\
\hline
\end{tabular}

Percent of nucleotide similarity of $d s b^{*}$.

*The values are \% of nucleotide sequence similarity for $1.3 \mathrm{~Kb}$ (16Sr RNA) and determined from pairwise aligment using DNASTAR software (MegAlign; DNASTAR, Inc., Madison, WI).

Accession Numbers are from GenBank.

bases. Sequence homology analyses were done for each of the nucleotide sequences and the deduced aa sequences from the partial GroES and GroEL reading frames. Nucleotide and aa sequence homologies with other members of the Ehrlichia genus are presented in Table 4. A phylogenetic tree based on multiple sequence alignment of the $1.249 \mathrm{~Kb}$ corresponding to groEL is presented in Figure 1B.

\section{Sequence analysis of $g / t A$ gene}

Primers gltAF1 and gltAR1 were designed in this study using information from $E$. canis genome [GenBank: CP000107] and E. chaffeensis gltA gene sequence [GenBank: AF304142]. The full length of gltA gene of $E$. mineirensis (UFMG-EV) was isolated. A single band of $\sim 1.5 \mathrm{~Kb}$ was obtained from the PCR reaction (data not shown). The full length gene of $1.251 \mathrm{~Kb}$ was obtained
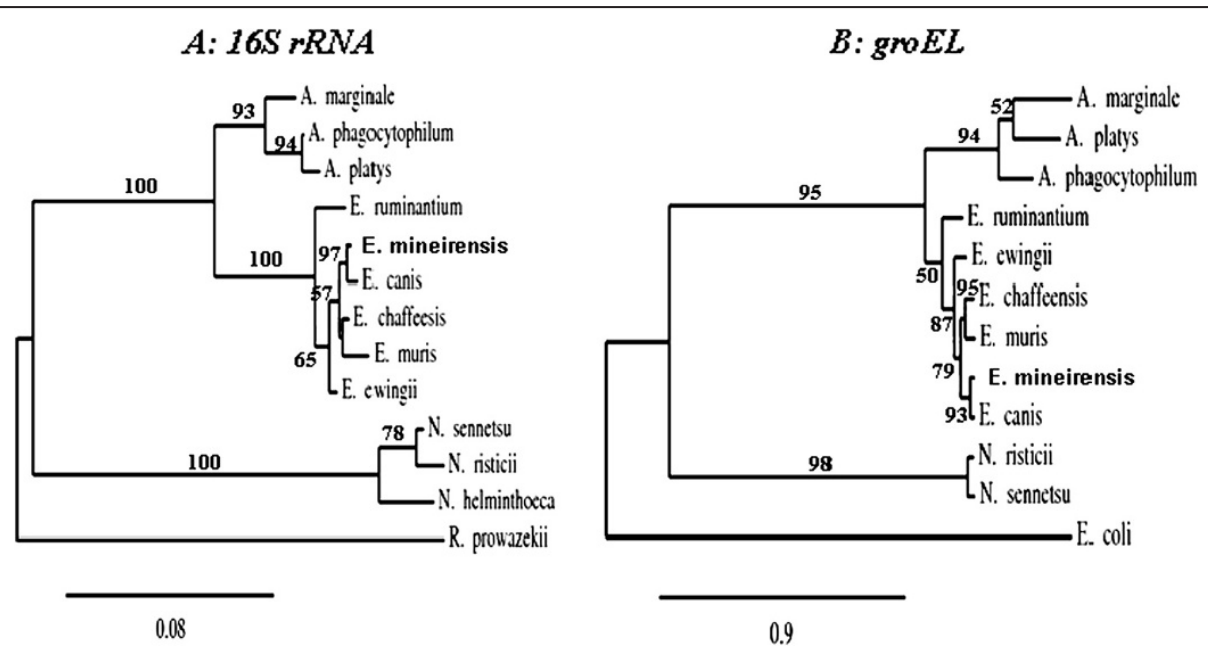

Figure $1 \mathrm{AB}$ Phylogenetic trees based on the $16 \mathrm{~S}$ rRNA (A) and groEL (B) genes sequences from members of the family Anaplasmataceae. The tree shows that E. mineirensis (UFMG-EV) falls in a clade separated from all the previous reported sequences. Bootstrap values are shown as \% in the internal branch. Only bootstrap values equal or higher than 50\% are shown. Rickettsia prowazekii 165 rRNA sequence was used to root the 165 rRNA tree and E.coli groEL gene was used to root the groEL tree. The GenBank accession numbers of the sequences used to build the 165 rRNA tree are: E. muris, AB013008; E. chaffeensis, AF147752; E. ruminantium, AF069758; E. ewingii, U96436; A. marginale, M60313; A. phagocytophilum, M73224; A. platys, M82801; N. helminthoeca, U12457; N. sennetsu, M73225; N. risticii, AF036649; E. canis, GU810149; R. prowazekii, NR044656. The GenBank accession numbers of the sequences used to build the groEL tree are: E. muris, AF210459; E. chaffeensis, L10917; E. ruminantium, U13638; E. ewingii, AF195273; A. marginale, AF165812; A. phagocytophilum, U96729; A. platys, AY008300; N. sennetsu, U88092; N. risticii, U96732; E. canis, U96731; E. coli, X07850. 


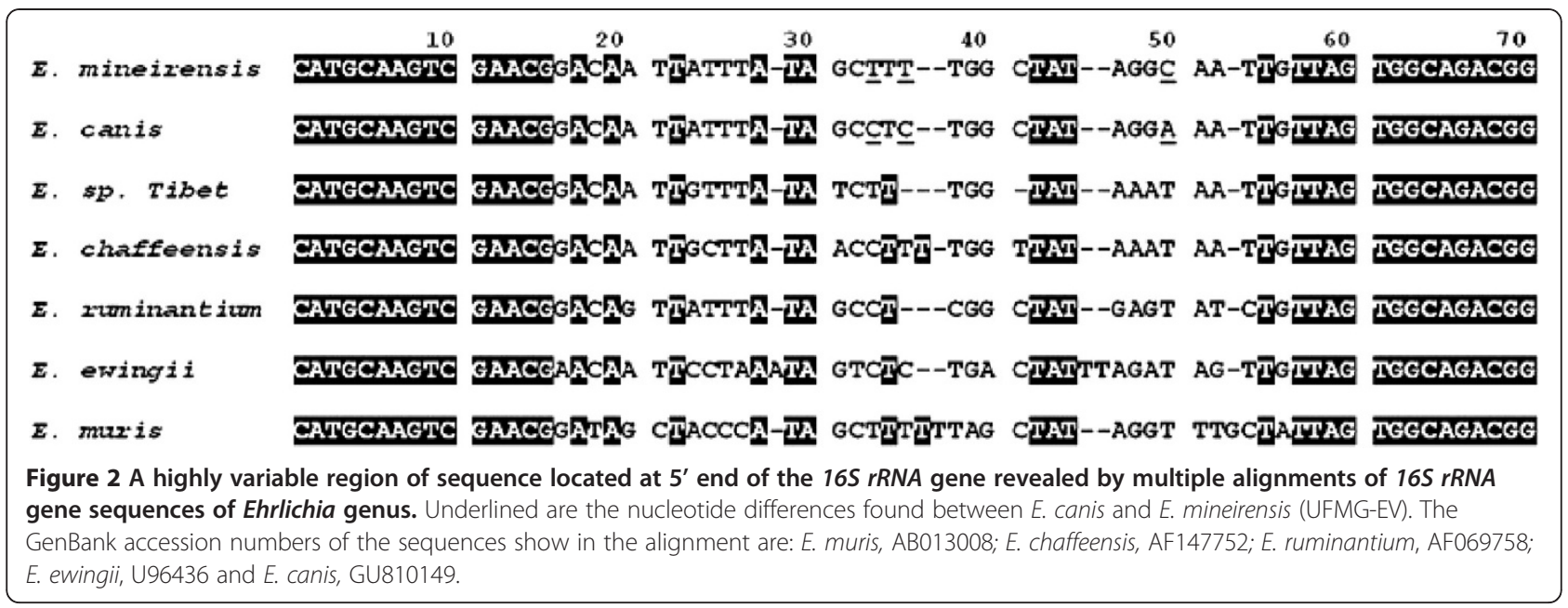

after sequencing and consensus analysis. The putative citrate synthase protein predicted using the $E$. mineirensis (UFMG-EV) gltA gene was 416 aa. Table 5 shows the nucleotide and the aa similarities with other members of the Ehrlichia genus. The gltA gene has been proposed as an alternative tool for the phylogenetic analysis of the genus Ehrlichia [7]. Using the maximum likelihood method we built a phylogenetic tree showing that E. mineirensis (UFMG-EV) falls in a clade apart from any previously reported gltA genes in the family Anaplasmataceae (Figure 4).

Sequence analysis of the gp36 gene and the putative encoded protein sequence

The gp 36 based PCR products derived from the isolate reported here had a molecular size of 1000 base pair (bp) (data not shown). Subsequent cloning of the PCR amplicons followed by sequencing showed that our gene was $0.948 \mathrm{~Kb}$ encoding a predicted protein with 315 aa and a molecular mass of $31.51 \mathrm{KDa}$ (28.89 KDa without the predicted 23-aa signal peptide). We found that the gp36 protein isolated in our study is a putative glycoprotein. The aa sequence of gp36 in our study has five potential sites of O-glycosylation and two of N-glycosylation. The O-carbohydrates were predicted to be linked to three serines (S) of the tandem repeat region at position 155, 164 and 173 and two threonines $(\mathrm{T})$ present in the post-repeat region at position 286 and 289. We explored as well the possibility to find $\mathrm{N}$-glycosylation on putative glycosylated asparagines $(\mathrm{N})$. Two sequons of $\mathrm{N}$-glycosylation (NXaa-T/S) at the pre-repeat region were found: NRS (at position 81) and NFS (at position 106).

Differences found in the Region I (The $5^{\prime}$ end pre-repeat region)

Alignment of the gp36 ortholog obtained in this study revealed that our sequence was 422 nucleotides in length encoding for 141 aa (Table 6). The nucleotide and predicted aa sequences exhibited relatively low identities, ranging from $54.9 \%$ to $91.2 \%$, and from $38.0 \%$ to $82.0 \%$, respectively, in comparison with related genes previously published for the gp36 orthologs in E. canis, E. chaffeensis and E. ruminantium [14] (Table 6).

Region II (the tandem repeat region)

Region II in E. mineirensis (UFMG-EV) contains 16 tandem repeats of $27 \mathrm{bp}$, each encoding nine aa. The single

Table 3 Unique aa changes in the carboxyl terminal of Ehrlichia mineirensis (UFMG-EV) dsb differ from $E$. canis dsb available in the GenBank

\begin{tabular}{|c|c|c|c|c|c|c|c|}
\hline \multirow[t]{2}{*}{ Isolates } & \multicolumn{7}{|c|}{ aa position ${ }^{1}$} \\
\hline & Identity $\%^{1}$ & 160 & 162 & 168 & 184 & 185 & 204 \\
\hline Ehrlichia canis [AF403710] & 100 & V & Q & $\mathrm{H}$ & $\mathrm{H}$ & Y & $T$ \\
\hline Ehrlichia canis Uberlandia [GU586135] & 100 & . & . & . & . & . & . \\
\hline Ehrlichia canis Sao Paulo [DQ460715] & 100 & . & . & . & . & . & . \\
\hline Ehrlichia canis Jaboticabal [DQ460716] & 100 & . & . & . & . & . & . \\
\hline Ehrlichia mineirensis (UFMG-EV) & 94.0 & A & K & $\mathrm{Y}$ & $N$ & $\mathrm{H}$ & A \\
\hline
\end{tabular}

1- Positions and \% of identities are based on the sequence of E. canis [GenBank: AF403710]. The dots below the aa letters mean conserved positions. Accession Numbers are from GenBank. 


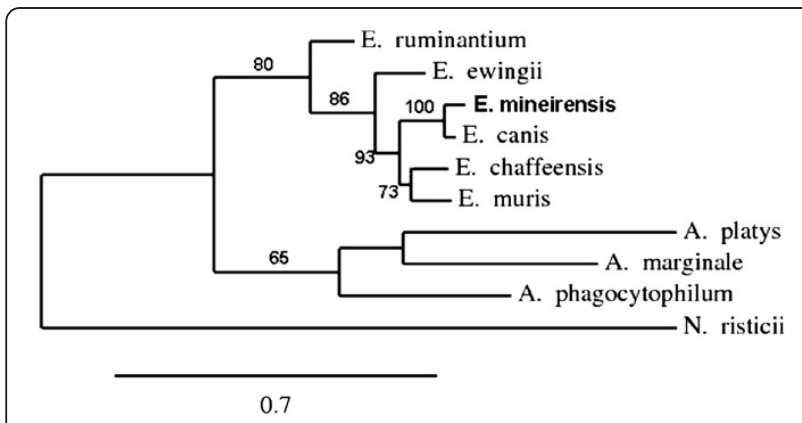

Figure 3 Phylogenetic unrooted tree based on the $d s b$ gene sequences from members of the family Anaplasmataceae. The tree shows that E. mineirensis (UFMG-EV) falls in a clade separated from all the previous reported sequences and the previously reported $E$. canis dsb sequences. Bootstrap values are show as\% in the internal branch. Only bootstrap values equal or higher than $50 \%$ are shown. The GenBank accession numbers of the dsb sequences used to build the tree are: E. canis, AF403710; E. canis Uberlandia, GU586135; E. canis Jaboticabal, DQ460716; E. canis Sao Paulo, DQ460715; E. muris, AY236484; E. chaffeensis, AF403711; E. ruminantium, AF308669, clon 18hw; E. ewingii, AY428950.

tandem repeat had the sequence VPAASGDAQ and was completely different to the sequences reported for glycoprotein orthologs of gp 36 E. canis, gp 47 E. chaffeensis and $E$. ruminantium mucin-like protein (Table 7). The tandem repeat of $E$. mineirensis (UFMG-EV) is a serine enriched area of the total protein sequence but does not contain threonine. Its glycoprotein gene shows a high $\mathrm{C}$ $+\mathrm{G}$ percent in the whole gene $(42.0 \%)$ and in the tandem repeat region $(52.1 \%)$.

\section{Region III (the 3' end post-repeat region)}

The comparison of region III among the orthologs show that it is a quite variable region, presenting differences in length, nucleotide and aa sequence. It has been widely revised by [14] and [15]. Our sequence was 94-bp length, which differ from any previously reported (data not shown). The percent identities of nucleotide and aa sequence in this region when compare with $E$. mineirensis
(UFMG-EV) go from 12.2\% (E. chaffeensis St Vincent, DQ146157) to $75 \%$ (E. canis TWN1, EF551366) and from $10 \%$ (E. chaffeensis St Vincent) to $32 \%$ (E. canis TWN1), respectively. E. ruminantium Highway mucinlike protein has $37.3 \%$ (bp) and 21\% (aa) of homology with $E$. mineirensis (UFMG-EV).

\section{B cell epitopes analysis}

The presence of B cell epitopes in the putative gp36 protein was predicted. The presence of one continuous $\mathrm{B}$ cell epitope was predicted in a highly hydrophobic repeat tandem region of our protein (197-212). Considering that gp36 (E. canis) and gp47 (E. chaffeensis) were the closest orthologs, we attempted to find B cell epitope in the tandem repeat of these species using the same algorithm employed for E. mineirensis (UFMG-EV). We found the presence of continuous B cell epitopes in the tandem repeat of E. canis gp36 [GenBank: EF560599] and E. chaffeensis gp47 [strain Arkansas, DQ085430 and strain St. Vincent, DQ146157]. The continuous epitopes found in these last three sequences were localized between the aa position 139-158, 195-225 and 203-218, respectively. The corresponding primary structures of the epitopes are shown in Figure 5A-E. We then compared the predicted 3D structures of the epitopes found in the gp36 orthologs in E. mineirensis (UFMG-EV), E. canis and the two from different strains of $E$. chaffeensis. We found that all epitopes were exposed on the surface of the predicted 3D structure of each protein. The superposition analysis of the epitopes 3D structure showed that they were structurally dissimilar with a root mean square deviation (rmsd) of 5-6 $\AA$ between the epitope of E. mineirensis (UFMG-EV) and others three Figure 5AE. A linear correlation between the rmsd and \% (dis) similarities among structure and sequences, respectively, is a valid interpretation for the evolution of homolog proteins [34]. Correlation for the epitopes of E. mineirensis (UFMG-EV) when compared with the other three orthologs gives an $\mathrm{R}^{2}=0.77$.

Table 4 Identities comparison of groEL gene and putative aa sequence between Ehrlichia mineirensis (UFMG-EV) and other members of Ehrlichia genus

\begin{tabular}{|c|c|c|c|c|c|c|}
\hline \multicolumn{7}{|c|}{ Percent of nucleotide (nt) similarity* } \\
\hline & E. mineirensis (UFMG-EV) & E. canis & E. chaffeensis & E. ewingii & E. muris & E. ruminantium \\
\hline Ehrlichia mineirensis (UFMG-EV) & $* * *$ & 97.2 (nt) & 92.3 (nt) & 91.0 (nt) & 92.0 (nt) & 87.3 (nt) \\
\hline Ehrlichia canis [U96731] & 99.0 (aа) & $* * *$ & 92.5 (nt) & 90.9 (nt) & $92.4(\mathrm{nt})$ & $87.6(\mathrm{nt})$ \\
\hline Ehrlichia chaffeensis [L10917] & $97.0(\mathrm{aa})$ & 97.0 (aa) & $* * *$ & 91.7 (nt) & 94.3 (nt) & $87.8(\mathrm{nt})$ \\
\hline Ehrlichia ewingii [AF195273] & 95.0 (aa) & 95.0 (aa) & 96.0 (aa) & $* * *$ & $91.5(\mathrm{nt})$ & $88.0(\mathrm{nt})$ \\
\hline Ehrlichia muris [AF210459] & $97.0(\mathrm{aa})$ & 97.0 (aa) & 99.0 (aа) & 97.0 (aа) & $* * *$ & 87.3 (nt) \\
\hline Ehrlichia ruminantium [U13638] & 92.0 (aa) & 92.0 (aa) & 93.0 (aa) & 92.0 (aa) & 93.0 (aa) & $* * *$ \\
\hline
\end{tabular}

Percent of amino acid (aa) similarity*.

*The values showed are \% of nucleotide and aa sequence similarity of $1.249 \mathrm{~Kb}$ determined from pairwise aligment using DNASTAR software (MegAlign; DNASTAR, Inc., Madison, WI) and 416 aa of the amino terminal determined from ClustalW.

Accession Numbers are from GenBank. 
Table 5 Identities comparison of gltA gene and putative aa sequence between $E$. mineirensis (UFMG-EV) and other members of Ehrlichia genus

\begin{tabular}{|c|c|c|c|c|c|c|}
\hline \multicolumn{7}{|c|}{ Percent of nucleotide (nt) similarity* } \\
\hline & E. mineirensis (UFMG-EV) & E. canis & E. chaffeensis & E. ewingii & E. muris & E. ruminantium \\
\hline Ehrlichia mineirensis (UFMG-EV) & $* * *$ & $94.3(\mathrm{nt})$ & 84.6 (nt) & 80.9 (nt) & 84.8 (nt) & 77.6 (nt) \\
\hline Ehrlichia canis [AF304143] & 94.0 (aa) & *** & 85.0 (nt) & 82.2 (nt) & $85.4(\mathrm{nt})$ & 79.0 (nt) \\
\hline Ehrlichia chaffeensis [AF304142] & 82.0 (aa) & 84.0 (aa) & $* * *$ & 82.0 (nt) & $87.0(\mathrm{nt})$ & 78.9 (nt) \\
\hline Ehrlichia ewingii [DQ365879] & 79.0 (aa) & 80.0 (aa) & 77.0 (aa) & $* * *$ & $82.5(\mathrm{nt})$ & 79.4 (nt) \\
\hline Ehrlichia muris [AF304144] & 82.0 (aa) & 84.0 (aa) & 85.0 (aa) & 78.0 (aa) & $* * *$ & 79.6 (nt) \\
\hline Ehrlichia ruminantium [AF304146] & 74.0 (aa) & 77.0 (aa) & 75.0 (aa) & 75.0 (aa) & 77.0 (aа) & $* * *$ \\
\hline
\end{tabular}

Percent of aa similarity*.

*The values showed are \% of nucleotide and aa sequence similarity of the full length determined from pairwise aligment using DNASTAR software (MegAlign; DNASTAR, Inc., Madison, WI) and the putative encoded aa determinated from ClustalW.

Accession Numbers are from GenBank.

\section{Discussion}

Polyphasic taxonomy has been advocated to ensure wellbalanced determinations of taxonomic relationships [7]. Different genes have been proposed to classify ehrlichial agents, however, the most widely used are $16 S$ rRNA [8,9], groESL operon [10], groEL gene [11], gltA [7], dsb [12], gp36, and gp19 [13].

Sequence comparison of the $16 \mathrm{~S} r R N A$ gene is recognized as one of the most powerful and precise methods for determining the phylogenetic relationships of bacteria $[8,11,35]$. Our results were consistent with previous phylogenetic analysis of Ehrlichia spp by using the $16 \mathrm{~S}$ $r R N A$ gene sequences $[9,36]$. In this study, our analysis of a relevant fragment of $16 S$ rRNA sequences revealed that the novel agent found in Brazilian $R$. (B.) microplus ticks was closely related to $E$. canis [GenBank: GU810149], but was also closely related to $E$. chaffeensis [GenBank: AF147752] showing $98.3 \%$ and $96.9 \%$ of homology, respectively. It is worth noting that the hypervariable region $16 \mathrm{~S} r R N A$ is well conserved in members of the same species (data not shown) and are different among members of Ehrlichia genus [8,9]. However, our hypervariable region of $16 \mathrm{~S} r R N A$ was different when compared with other members of Ehrlichia genus.

Since the $16 S$ rRNA gene is known to exhibit a high level of structural conservation with a low evolutionary rate, levels of sequence divergence greater than $0.5 \%$ in comparisons with nearly complete $16 S$ rRNA gene sequences of members of the genus Ehrlichia have been considered sufficient to classify organisms as different species $[8,35]$. The levels of divergence of the $16 S$ rRNA sequence between this novel Brazilian ehrlichial agent and the closest member of the Anaplasmataceae, $E$. canis was $1.7 \%$ in pairwise comparisons of 1384 base sequences (data not shown), and this level of difference should be sufficient to classify the novel ehrlichial agent as a new species of the genus Ehrlichia. Furthermore, the $16 S$ rRNA phylogenetic tree constructed with a maximum likelihood method show that E. mineirensis (UFMG-EV) falls in a different clade separated from any previously reported Ehrlichia spp.

The genes groEL [11] and gltA [7] have been proposed as an alternative to $16 S$ rRNA for the phylogenetic analysis of the Anaplasmatacaea family as they are less

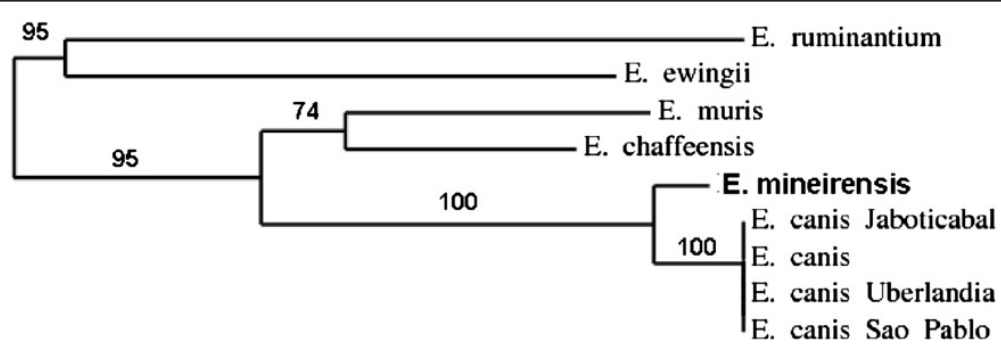

0.1

Figure 4 Phylogenetic tree based on the citrate synthase $(g / t A)$ gene sequences from members of the family Anaplasmataceae. The tree shows that E. mineirensis (UFMG-EV) falls in a clade separated from all the previously reported sequences. Bootstrap values are show as \% in the internal branch. Only are showed bootstrap values equal or higher than 50\%. N. risticii gltA sequence was used to root the tree. The GenBank accession numbers of the gltA sequences used to build the tree are as follow: E. canis, AF304143; E. muris, AF304144; E. chaffeensis, AF304142; E. ruminantium, AF304146; E. ewingii, DQ365879; A. marginale, AF304140; A. phagocytophilum, AF304138; A. platys, AY077620. 
Table 6 Length and percent of nucleotide and aa homology of the 5' end pre-repeat region between the orthologs of gp36 in Ehrlichia mineirensis (UFMG-EV) and related genes

\begin{tabular}{|c|c|c|c|c|c|}
\hline \multirow[b]{2}{*}{ Source } & \multirow[b]{2}{*}{ Strain } & \multicolumn{2}{|c|}{ Nucleotide } & \multicolumn{2}{|c|}{ aa } \\
\hline & & Length $^{1}$ & Homology $y^{2}$ & Length $^{3}$ & Homology ${ }^{4}$ \\
\hline Ehrlichia mineirensis & (UFMG-EV) & 422 & - & 141 & - \\
\hline \multirow[t]{4}{*}{ Ehrlichia canis gp 36} & TWN1 [EF551366] & 425 & 91.2 & 142 & 82 \\
\hline & Louisiana [DQ146151] & 428 & 88.2 & 143 & 78 \\
\hline & Sao Paulo [DQ146154] & 428 & 88.4 & 143 & 78 \\
\hline & Cameroon [DQ146155] & 428 & 88.6 & 143 & 79 \\
\hline \multirow[t]{4}{*}{ Ehrlichia chaffeensis gp47 } & Arkansas [DQ085430] & 471 & 61.8 & 157 & 52 \\
\hline & Sapulpa [DQ085431] & 461 & 62.1 & 154 & 53 \\
\hline & Jax [DQ146156] & 461 & 60.7 & 154 & 51 \\
\hline & St Vincent [DQ146157] & 461 & 62.1 & 154 & 53 \\
\hline Ehrlichia ruminantium mucin-like protein & Highway [AF308673] & 410 & 54.9 & 137 & 38 \\
\hline
\end{tabular}

1 - The length were determinate using the Tandem Repeats Finder database [30].

2 - Percent of nucleotide homology were calculated with MegAlign, DNAStar, USA. Comparing with E. mineirensis (UFMG-EV).

3 - The length was determined using ClustalW [20] in comparison with Ehrlichia mineirensis (UFMG-EV).

4 - Percent of aa homology were calculated with ClustalW [20]. Comparing with E. mineirensis (UFMG-EV).

Accession Numbers are from GenBank.

conserved than $16 S$ rRNA among the family members [7] and $d s b$ gene has been previously used to classified members of the Ehrlichia genus [12]. It is important to note that the spacer of the groESL operon was $95 \mathrm{bp}$ in E. mineirensis (UFMG-EV), which differs from the reported for E. canis, E. chaffeensis, E. ruminantium with 93, 100 and $96 \mathrm{bp}$, respectively [10]. The gp36 orthologs are a divergent gene in E. canis, E. chaffeensis and $E$. ruminantium due to their high evolutionary pressure $[14,15]$. This gene has been used to differentiate new isolates of $E$. canis where $16 S$ rRNA was not well suited to discriminate between $E$. canis isolates [13].
In our study the level of similarity among ehrlichial gltA and $d s b$ were lower than that of $16 S$ rRNA and groEL gene sequences in the genus Ehrlichia. E. canis was the closest Ehrlichia species to E. mineirensis (UFMG-EV) in all the studied genes. Similar phylogenetic relationships are observed between other members of the Ehrlichia genus - i.e., E. chaffeensis/E. muris, N. risticii/N. sennetsu and A. marginale/A. platys.

The architecture of gltA, groEL and $d s b$ based phylogenetic trees were similar to that of the tree derived from the $16 S$ rRNA gene sequences. However, the trees constructed from glt $A$ and $d s b$ show more divergence

Table 7 Summary of Ehrlichia tandem repeats present in gp36 glycoprotein orthologs

\begin{tabular}{|c|c|c|c|c|c|}
\hline \multirow[b]{2}{*}{ Source } & \multirow[b]{2}{*}{ Strain } & \multicolumn{3}{|c|}{ Repeat } & \multirow[b]{2}{*}{ Consensus tandem repeat sequence $(\mathrm{aa})^{2}$} \\
\hline & & $\begin{array}{l}\text { Length } \\
(\mathrm{bp})^{1}\end{array}$ & No. ${ }^{1}$ & $\begin{array}{l}\text { Homology } \% \\
\text { (bp) })^{1}\end{array}$ & \\
\hline Ehrlichia mineirensis & (UFMG-EV) & 27 & 16.0 & 100 & VPAASGDAQ \\
\hline \multirow[t]{5}{*}{ Ehrlichia canis gp36 } & TWN1 [EF551366] & 27 & 13.2 & 100 & TEDSVSAPA \\
\hline & Louisiana [DQ146151] & 27 & 5.2 & 99 & $\ldots \ldots$ \\
\hline & Sao Paulo [DQ146154] & 27 & 18.2 & 100 & . \\
\hline & Cameroon [DQ146155] & 27 & 16.2 & 100 & $\ldots \ldots$ \\
\hline & IS [EF636663] & 27 & 11.2 & 99 & TEDPVSATA \\
\hline \multirow[t]{4}{*}{ Ehrlichia chaffeensis gp47 } & Arkansas [DQ085430] & 57 & 7.0 & 99 & ASVSEGDAWNAVSQETPA \\
\hline & Sapulpa [DQ085431] & 99 & 4.5 & 99 & EGNASEPWSQEAAPVSESGDAANPVSSSENAS \\
\hline & $\operatorname{Jax}[\mathrm{DQ} 146156]$ & 99 & 4.5 & 98 & $\ldots \ldots \ldots \ldots \ldots \ldots \ldots$ \\
\hline & St Vincent [DQ146157] & 99 & 3.4 & 98 & $\ldots$ \\
\hline \multirow{3}{*}{$\begin{array}{l}\text { Ehrlichia ruminantium } \\
\text { mucin-like protein }\end{array}$} & Highway [AF308673] & 27 & 21.7 & 99 & VTSSPEGSV \\
\hline & Welgevonden [CR767821] & 27 & 56.0 & 95 & $\ldots \ldots$ \\
\hline & Gardel [CR925677] & 66 & 16.9 & 99 & SSEVTESNQGSSASWGDAGVQ \\
\hline
\end{tabular}

1 - The length (bp), No of nucleotide repeats and the \% of Homology were determinate using the Tandem Repeats Finder database [21].

2 - The dots below the tandems mean conserved aa sequence.

Accession Numbers are from GenBank. 


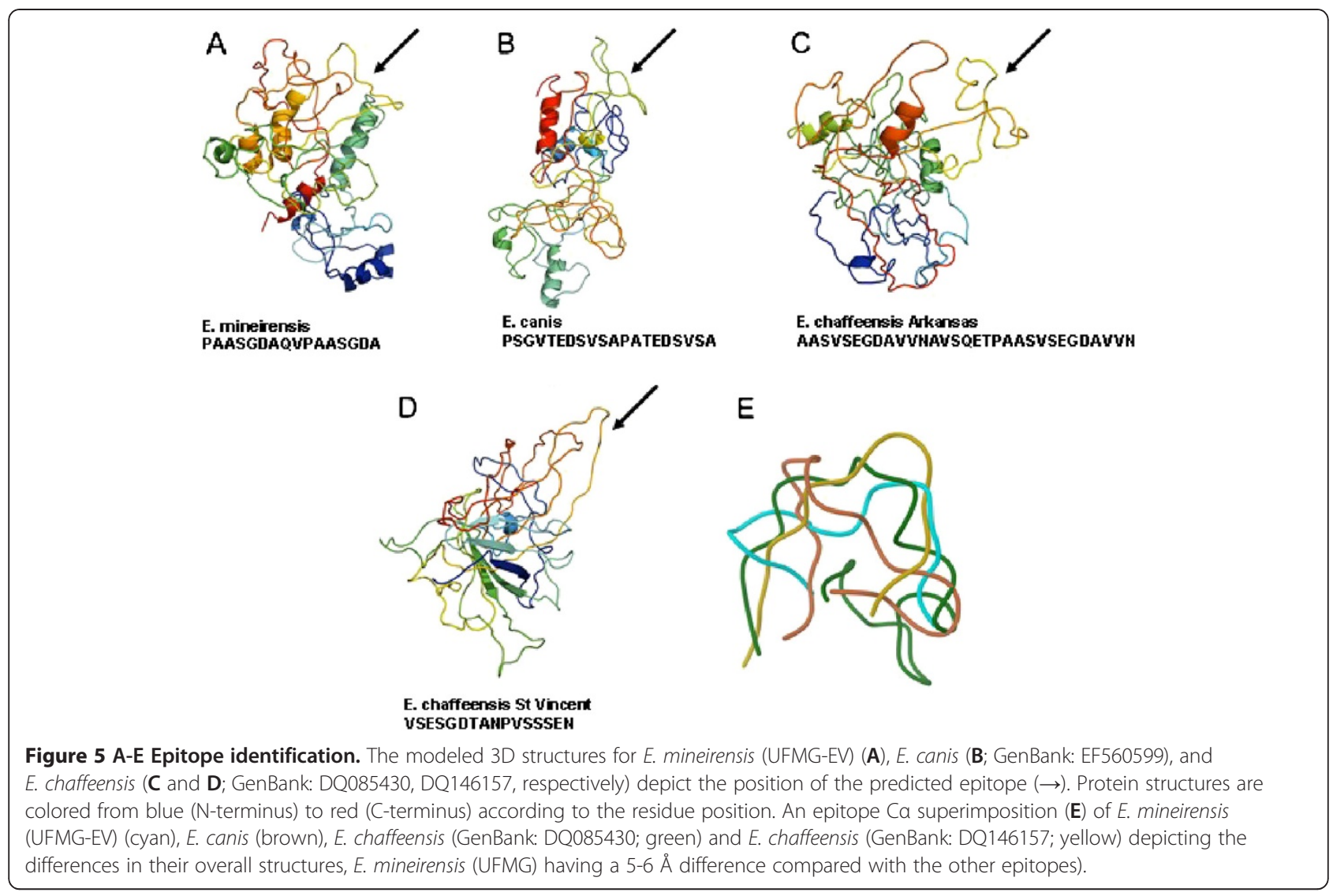

than that from the $16 S$ rRNA and groEL gene. The difference of E. canis and E. mineirensis (UFMG-EV) was well established in all the four trees based on nucleotide sequences. E. mineirensis (UFMG-EV) was well defined, with higher bootstrap values in the gltA (100) and $d s b$ (100) based trees than for those of the 16S rRNA (97) and groEL (93) based tree.

Based on aa homology and genomic synteny analyses, it has been determined that the mucin-like protein of Ehrlichia ruminantium, gp36 of E. canis and gp47 of E. chaffeensis are orthologs [14]. Identity of $87.2 \%$ has been found in the pre-repeat region among geographically distant $E$. canis isolates [13]. The single tandem repeat was highly conserved among isolates (TEDSVSAPA) with variations in the number of repeats [13-15] and few conservative changes in amino acid sequences [15]. The tandem repeat genetic unit varies in length (from $27 \mathrm{bp}$ - 99 bp) among the different orthologs, number of repeats (from 3.4 - 56) and the homology of the nucleotide and the aa sequence encoded in the repeat (Table 7). Our sequence contains a tandem repeat that shares an extremely low homology with the gp36 orthologs reported until now ranging from $22 \%$ (E. ruminantium and $E$. canis) to 33\% (E. chaffeensis). Doyle et al. [14] describes gp 36 and gp47 as glycoprotein sharing O-glycosylation predicted sites in the serines and threonines of the tandem repeat. It is noteworthy that the tandem repeat of our sequence does not contain threonine; nevertheless, we predicted three sites of O-glycosylation in the serines of the tandem repeat and two in threonines of the postrepeat region. Two $\mathrm{N}$-glycosylation sites were found in our aa sequence. The analysis for $\mathrm{N}$-glycosylation was done for E. ruminantium, E. canis and for E. chaffeensis ortholog sequences (data not shown) and potential sites of $\mathrm{N}$-glycosylation were found as well for these sequences. Glycosylation plays a crucial role in the immunogenicity of these glycoproteins $[14,15]$. Deglycosylation of the gp36 tandem repeat drastically reduces its immunogenicity [14]. Both gp36 and gp 47 are described as the major immunoreactive protein of $E$. canis and $E$. chaffeensis and the tandem repeats contain the major antibody epitope $[14,15]$. It was found that the tandem repeat of gp36 from E. mineirensis (UFMG-EV) contain the major $\mathrm{B}$ cell epitope previously reported for the glycoprotein orthologs. The prediction of the 3D structure of the B cell epitopes present in the tandem repeat shows a high structural divergence among the closest gp36 orthologs in E. mineirensis (UFMG-EV), E. canis and E. chaffeensis. These structural differences may explain the results obtained by Doyle et al. [14] in which neither gp36 nor gp47 reacted with heterologous antisera. 
The $\mathrm{C}+\mathrm{G}$ content of the gp36 gene of E. mineirensis (UFMG-EV) is higher than the rest of the orthologs previously reported (data not shown). The $\mathrm{C}+\mathrm{G}$ content in specific genes have been used in systematics as support for the classification of organisms [7], and it is known that recombination significantly increases the silent $\mathrm{C}+$ $\mathrm{G}$ content of a genome in a selectively neutral manner [37].

Although it is well known that Babesia bovis, B. bigemina and Anaplasma marginale are the most common etiological agents transmitted by $R$. (B.) microplus ticks [38], the detection of any species of Ehrlichia in $R$. (B.) microplus ticks has been infrequently reported. The first two reports were in China in the Guangxi Autonomous Region in 1999 [39] and Tibet in 2002 [8]; the second in Thailand in 2003 [36] and the latest one in Xiamen, China in 2011 [40]. Except the isolate from Guangxi, $E$. canis [39], the rest share, based on $16 S$ rRNA, a $99.9 \%$ of homology $[36,40]$ and differ from the ehrlichial species previously reported and classified as Ehrlichia spp strain Tibet [8]. In the present study, determined by pairwise alignment, the E. mineirensis (UFMG-EV) isolated from $R$. (B.) microplus shares $97 \%$ of similarity with the $16 S$ $r R N A$ sequences of the referred species (data not shown). This is the second report of a new Ehrlichia spp isolated from $R$. (B.) microplus, but the first to be reported in the American continent. The identification of $E$. mineirensis (UFMG-EV) in $R$. (B.) microplus ticks suggests a potential of infection and transmission of this agent to cattle in the area where infected ticks are present.

\section{Conclusions}

Based on the molecular and phylogenetic analysis of the genes $16 S$ rRNA, groEL, $d s b$ and gltA we concluded that the new microorganism isolated from the hemolymph of $R$. (B.) microplus is a new species of Ehrichia with new predicted antigenic properties in the gp36 glycoprotein ortholog. Complementary analysis of $\mathrm{C}+\mathrm{G}$ content in the gp36 orthologs, distant of groESL spacer and hypervariable region of $16 S$ rRNA supports the fact that E. mineirensis (UFMG-EV) is a separate phylogenetic entity.

Further studies should address the question whether $R$. (B.) microplus is a competent vector for this and other Ehrlichia species and whether this new organism is an emerging pathogen for cattle or an endosymbiont of $R$. (B.) microplus.

\section{Competing interests}

The authors declare that they have no competing interest.

\section{Authors' contributions}

AC performed the isolation of the genes, the interpretation of the molecular, in silico immunological data and drafted the manuscript. EZ performed the in vitro cultivation and maintenance of the microorganism at LMU. MFBR isolated the organism from ticks and established it in vitro. JAGS performed the in vitro cultivation and maintenance of the microorganism at UFMG. JF contributed to design the molecular and phylogenetic analyses. LG contributed to the overall design and supervision of the study. JJV performed the 3D structure prediction and contributed with the epitope analysis. LP developed the conception and design of the study and contributed in drafting the manuscript. All authors critically revised the manuscript and have given final approval of the version to be published.

\section{Acknowledgments}

The authors thank Dr Ulrike G. Munderloh (University of Minnesota, USA) for permission to use the IDE8 cell line. A. Cabezas Cruz is a Marie Curie Early Stage Researcher (ESR) supported by the POSTICK ITN (Post-graduate training network for capacity building to control ticks and tick-borne diseases) within the FP7- PEOPLE - ITN programme (EU Grant No. 238511).

\section{Author details}

'University of South Bohemia, Faculty of Science, České Budějovice, Czech Republic. ${ }^{2}$ Comparative Tropical Medicine and Parasitology, Ludwig-Maximilians-Universität München, Munich, Germany. ${ }^{3}$ Departamento de Parasitologia, ICB-UFMG, Belo Horizonte, Brazil. ${ }^{4}$ Instituto de Investigación de Recursos Cinegéticos, IREC, Ciudad Real, Spain. ${ }^{5}$ Department of Veterinary Pathobiology, Center for Veterinary Health Sciences, Oklahoma State University, Oklahoma, USA. ${ }^{6}$ Departamento de Medicina Veterinaria Preventiva, INCT-Pecuária, Escola de Veterinária-UFMG, Belo Horizonte, Minas Gerais, Brazil.

Received: 17 October 2012 Accepted: 3 December 2012

Published: 11 December 2012

\section{References}

1. Doyle KC, Labruna MB, Breitschwerdt EB, Tang YW, Corstvet RE, Hegarty BC, Bloch KC, Li P, Walker DH, McBride JW: Detection of medically important Ehrlichia by quantitative multicolor TaqMan real-time polymerase chain reaction of the dsb gene. J Mol Diagn 2005, 7(4):504-510.

2. Rikihisa Y: Anaplasma phagocytophilum and Ehrlichia chaffeensis: subversive manipulators of host cells. Nat Rev Microbiol 2010, 8:328-339.

3. Telford SR III, Goethert HK, Cunningham JA: Prevalence of Ehrlichia muris in Wisconsin deer ticks collected during the mid 1990s. The Open Microbiol J 2011, 5:18-20.

4. Allsopp MTEP, Louw M, Meyer EC: Ehrlichia ruminantium: an emerging human pathogen? Ann NY Acad Sci 2005, 1063:358-360.

5. Da Costa VRF, Biondo AW, Sá Guimarăes AM, Dos Santos AP, Dos Santos RP, Dutra LH, De Paiva DPPV, De Morais HA, Messick JB, Labruna MB, Vidotto O: Ehrlichiosis in Brazil. Rev Bras Parasitol Vet Jaboticabal 2011, 20(1):1-12.

6. Rar V, Golovljova I: Anaplasma, Ehrlichia, and "Candidatus Neoehrlichia" bacteria: pathogenicity, biodiversity, and molecular genetic characteristics, a review. Infect Gen and Evol 2011, 11(8):1842-1861.

7. Inokuma H, Brouqui $P$, Drancourt M, Raoult D: Citrate synthase gene sequence: a new tool for phylogenetic analysis and identification of Ehrlichia. J Clin Microbiol 2001, 39(9):3031-3039.

8. Wen B, Jian R, Zhang Y, Chen R: Simultaneous detection of Anaplasma marginale and a new Ehrlichia species closely related to Ehrlichia chaffeensis by sequence analyses of 16S ribosomal DNA in Boophilus microplus ticks from Tibet. J Clin Microbiol 2002, 40(9):3286-3290.

9. Warner CK, Dawson JE: Genus- and species-level identification of Ehrlichia species by PCR and sequencing. In PCR protocols for emerging infectious diseases. Edited by Persing DH. Washington DC: ASM Press; 1996:100-105.

10. Sumner JW, Nicholson WL, Massung RF: PCR amplification and comparison of nucleotide sequences from the groESL heat shock operon of Ehrlichia species. J Clin Microbiol 1997, 35(8):2087-2092.

11. Yu XJ, Zhang XF, McBride JW, Zhang Y, Walker DH: Phylogenetic relationships of Anaplasma marginale and 'Ehrlichia platys' to other Ehrlichia species determined by GroEL aa sequences. Int J Syst Evol Microbiol 2001, 51(3):1143-1146.

12. Sacchi ABV, Duarte JMB, André MR, Machado RZ: Prevalence and molecular characterization of Anaplasmataceae agents in free-ranging Brazilian marsh deer (Blastocerus dichotomus). Comp Immun Microbiol and Inf Dis 2012, 35(4):325-334.

13. Hsieh YC, Lee CC, Tsang CL, Chung YT: Detection and characterization of four novel genotypes of Ehrlichia canis from dogs. Vet Microbiol 2010, 146(1-2):70-75. 
14. Doyle CK, Nethery KA, Popov VL, McBride JW: Differentially expressed and secreted major immunoreactive protein orthologs of Ehrlichia canis and E. chaffeensis elicit early antibody responses to epitopes on glycosylated tandem repeats. Infect Immun 2006, 74(1):711-720.

15. Zhang X, Luo T, Keysary A, Baneth G, Miyashiro S, Strenger C, Waner T, McBride JW: Genetic and antigenic diversities of major immunoreactive proteins in globally distributed Ehrlichia canis strains. Clin and Vacc Immun 2008, 15(7):1080-1088.

16. Zweygrath E, Schöl H, Lis K, Cabezas Cruz A, Thiel C, Silaghi C, Ribeiro MFB, Passos LMF: In vitro culture of a new genotype of Ehrlichia sp. from Brazil. Orvieto: Joint Conference on Emerging and Re-emerging Epidemics Affecting Global Health 2012; 2012. Proceedings.

17. Munderloh UG, Liu Y, Wang M, Chen C, Kurtti TJ: Establishment, maintenance and description of cell lines from the tick Ixodes scapularis. J Parasitol 1994, 80(4):533-543.

18. Munderloh UG, Kurtti TJ: Formulation of medium for tick cell culture. Exp Appl Acarol 1989, 7(3):219-229.

19. Dumler JS, et al: Reorganization of genera in the families Rickettsiaceae and Anaplasmataceae in the order Rickettsiales: unification of some species of Ehrlichia with Anaplasma, Cowdria with Ehrlichia and Ehrlichia with Neorickettsia, descriptions of six new species combinations and designation of Ehrlichia equi and 'HGE agent' as subjective synonyms of Ehrlichia phagocytophila. Int J Syst Evol Microbiol 2001, 51(6):2145-2165.

20. Zhang Z, Schwartz S, Wagner L, Miller W: A greedy algorithm for aligning DNA sequences. J Comput Biol 2000, 7(1-2):203-214.

21. Thompson JD, Higgins DG, Gibson TJ: CLUSTALW: improving the sensitivity of progressive multiple sequence alignment through sequence weighting, position-specific gap penalties and weight matrix choice. Nucleic Acids Res 1994, 22(22):4673-4680.

22. ExPASy Translation Tool: ExPASy Translation Tool. http://expasy.hcuge.ch/ tools/dna.html.

23. Edgar RC: MUSCLE: multiple sequence alignment with high accuracy and high throughput. Nucleic Acids Res 2004, 32(5):1792-1797.

24. Castresana J: Selection of conserved blocks from multiple alignments for their use in phylogenetic analysis. Mol Biol Evol 2000, 17(4):540-552.

25. Guindon S, Gascuel O: A simple, fast, and accurate algorithm to estimate large phylogenies by maximum likelihood. Syst Biol 2003, 52(5):696-704.

26. Anisimova M, Gascuel O: Approximate likelihood ratio test for branchs: a fast, accurate and powerful alternative. Syst Biol 2006, 55(4):539-552.

27. Chevenet F, Brun C, Banuls AL, Jaca B, Chisten R: TreeDyn: towards dynamic graphics and annotations for analyses of trees. BMC Bioinf 2006, 10(7):439.

28. Nielsen $\mathrm{H}$, Engelbrecht J, Brunak S, von Heijne G: Identification of prokaryotic and eukaryotic signal peptides and prediction of theircleavage sites. Protein Eng 1997, 10(1):1-6.

29. Julenius K, Molgaard A, Gupta R, Brunak S: Prediction, conservation analysis, and structural characterization of mammalian mucin type Oglycosylation sites. Glycobio/ 2005, 15(2):153-164.

30. NetNGlyc 1.0 Server. http://www.cbs.dtu.dk/services/NetNGlyc/.

31. Benson G: Tandem repeats finder: a program to analyze DNA sequences. Nucleic Acids Res 1999, 27(2):573-580.

32. Ponomarenko JV, Bourne PE: Antibody-protein interactions: benchmark datasets and prediction tools evaluation. BMC Struct Biol 2007, 7:64-83.

33. Ponomarenko J, Bui HH, Li W, Fusseder N, Bourne PE, Sette A, Peters B: ElliPro: a new structure-based tool for the prediction of antibody epitopes. BMC Bioinf 2008, 9:514-521.

34. Wood TC, Pearson WR: Evolution of protein sequences and structures. J Mol Biol 1999, 291:977-995.

35. Woese CR: Bacterial evolution. Microbiol Rev 1987, 51(2):221-271.

36. Parola P, Cornet JP, Sanogo YO, Miller RS, Thien HV, Gonzalez JP, Raoult D, Telford SR III, Wongsrichanalai C: Detection of Ehrlichia spp., Anaplasma spp., Rickettsia spp., and other eubacteria in ticks from the Thai-Myanmar border and Vietnam. J Clin Microbiol 2003, 41(4):1600-1608.

37. Birdsell JA: Integrating genomics, bioinformatics, and classical genetics to study the effects of recombination on genome evolution. Mol Biol Evol 2002, 19(7):1181-1197.

38. Alonso M, Arellano-Sota C, Cereser VH, Cordoves CO, Guglielmone AA, Kessler R, Mangold AJ, Nari A, Patarroyo JH, Solari MA, Vega CA, Vizcaino O, Camus E: Epidemiology of bovine anaplasmosis and babesiosis in Latin America and the Caribbean. Vet Sci Tech Off Int Epiz 1992, 11(3):713-733.
39. Pan $\mathrm{H}$, et al: Amplification of $16 \mathrm{~S}$ rRNA gene fragments of Ehrlichia canis from ticks in southern China. Chin J Zoon 1999, 15(3):3-6.

40. Jiang BG, Cao WC, Niu JJ, Wang JX, Li HM, Sun Y, Yang H, Richadus JH, Habbema JD: Detection and identification of Ehrlichia species in Rhipicephalus (Boophilus) microplus ticks in cattle from Xiamen China. Vector Borne Zoon Dis 2011, 11(3):325.

doi:10.1186/1756-3305-5-291

Cite this article as: Cruz et al:: New species of Ehrlichia isolated from Rhipicephalus (Boophilus) microplus shows an ortholog of the $E$. canis major immunogenic glycoprotein gp36 with a new sequence of tandem repeats. Parasites \& Vectors 2012 5:291.

\section{Submit your next manuscript to BioMed Central and take full advantage of:}

- Convenient online submission

- Thorough peer review

- No space constraints or color figure charges

- Immediate publication on acceptance

- Inclusion in PubMed, CAS, Scopus and Google Scholar

- Research which is freely available for redistribution
C Biomed Central 